Erratum

\title{
Erratum to "Eradication of HCV Infection with the Direct-Acting Antiviral Therapy in Renal Allograft Recipients"
}

\author{
Armando Calogero $\left(\mathbb{D},{ }^{1}\right.$ Evangelista Sagnelli $\left(D,{ }^{2}\right.$ Massimiliano Creta, ${ }^{3}$ \\ Silvia Angeletti $\left(\mathbb{D},{ }^{4}\right.$ Gaia Peluso $\left(\mathbb{D},{ }^{1}\right.$ Paola Incollingo $\left(\mathbb{D},{ }^{1}\right.$ Maria Candida, \\ Gianluca Minieri, ${ }^{1}$ Nicola Carlomagno, ${ }^{1}$ Concetta Anna Dodaro, ${ }^{1}$ \\ Massimo Ciccozzi, ${ }^{5}$ and Caterina Sagnelli $\mathbb{D D}^{2}$ \\ ${ }^{1}$ Department of Advanced Biomedical Sciences, University of Naples Federico II, Naples, Italy \\ ${ }^{2}$ Department of Mental Health and Public Medicine, University of Campania Luigi Vanvitelli, Naples, Italy \\ ${ }^{3}$ Department of Neurosciences, Human Reproduction and Odontostomatology, University of Naples Federico II, Naples, Italy \\ ${ }^{4}$ Unit of Clinical Laboratory Science, University Campus Bio-Medico of Rome, Rome, Italy \\ ${ }^{5}$ Unit of Medical Statistic and Molecular Epidemiology, University Campus Bio-Medico, Rome, Italy
}

Correspondence should be addressed to Caterina Sagnelli; caterina.sagnelli@unicampania.it

Received 2 July 2019; Accepted 4 July 2019; Published 15 July 2019

Copyright (c) 2019 Armando Calogero et al. This is an open access article distributed under the Creative Commons Attribution License, which permits unrestricted use, distribution, and reproduction in any medium, provided the original work is properly cited.

In the article titled "Eradication of HCV Infection with the Direct-Acting Antiviral Therapy in Renal Allograft Recipients" [1], the first and last names of all the authors were reversed. The revised authors' list is shown above and updated in place.

\section{References}

[1] A. Calogero, E. Sagnelli, M. Creta et al., "Eradication of $\mathrm{HCV}$ infection with the direct-acting antiviral therapy in renal allograft recipients," BioMed Research International, vol. 2019, Article ID 4674560, 8 pages, 2019. 


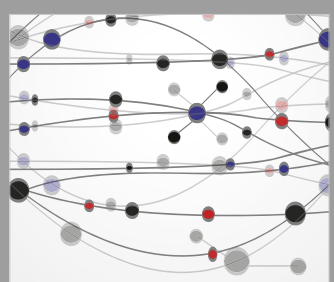

The Scientific World Journal


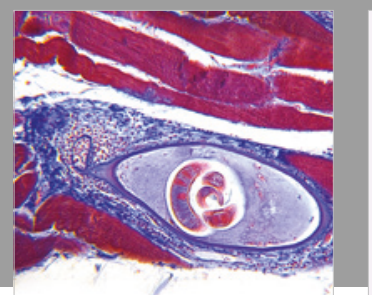

Gastroenterology Research and Practice



\section{Hindawi}

Submit your manuscripts at

www.hindawi.com
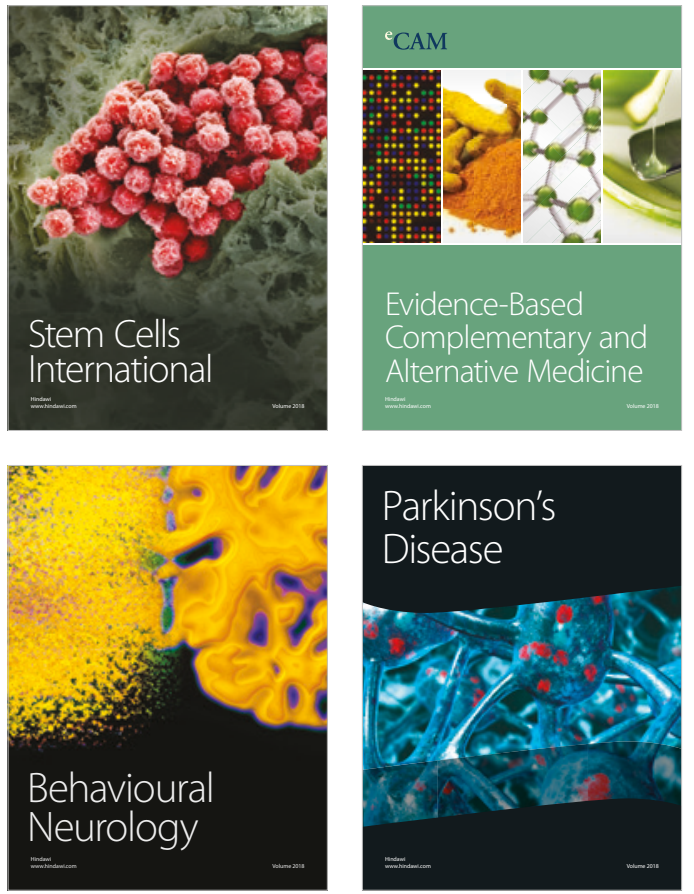



ournal of

Diabetes Research

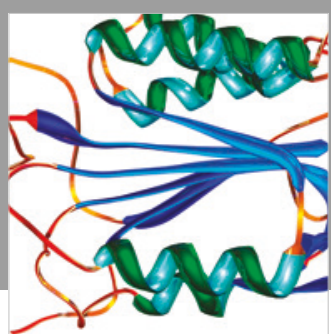

Disease Markers
